\title{
Preface to the Special Issue on Geo-Disasters
}

\author{
Chong Xu ${ }^{* 1,2}$, Xiwei $\mathrm{Xu}^{1,2}$, Yu Huang ${ }^{3}$ \\ 1. National Institute of Natural Hazards, Ministry of Emergency Management of China, Beijing 100085, China \\ 2. Key Laboratory of Compound and Chained Natural Hazards Dynamics (Under Construction), Ministry of Emergency \\ Management of China, Beijing 100085, China \\ 3. College of Civil Engineering, Tongji University, Shanghai 200092, China \\ (ii) Chong Xu: https://orcid.org/0000-0002-3956-4925
}

Exploring the mechanism of natural disasters and fighting against natural disasters are the eternal themes for human survival and development. Geo-disasters are one kind of natural hazards, including landslides, debris flows, earthquakes, liquefactions, which can result in serious causalities and economic loss. Therefore, geo-disaster prevention and reduction has been a grand research topic for many decades and a large number of achievements have been made in detection, monitoring, early warning and risk assessment of geo-disasters (Vilímek et al., 2020; Ritchie and Roser, 2019; Xu et al., 2016; Xu, 2015; Huang et al., 2014). However, the climate change caused by global warming and effects of human activities, geo-disasters occur from time to time and the risk remains high, which brings new challenges to scientific and technological experts in this field all over the world (Xu and Xu, 2021; McGlade et al., 2019; Xiong and Huang, 2019; Keller et al., 2015; Huang and Cheng, 2013). In order to track the state-of-the-art research results in geo-disaster prevention and reduction, a few months ago, we started to organize a special issue "geo-disasters" to show the new theories, methods and technical research results in this field. Eventually, we successfully collected 13 research papers, covering the topics of earthquake-triggered landslide and identification, landslide stability analysis, debris flow, liquefactions, paleoearthquakes, and ground motion response. This special issue includes not only the basic theoretical research and model development, but also the application of new technologies in geo-disaster prevention and control engineering. We hope that this special issue can arouse the interest of readers and promote the theoretical and technical research of geo-disasters and the technical work of disaster prevention and reduction.

Major earthquakes can trigger devastating landslide, especially in rugged mountainous areas. It is very important to compile and record a complete and detailed map of earthquake-triggered landslides and analyze their spatial distribution pattern, providing a basis for subsequent landslide evolution analysis and hazard assessment (Xu et al., 2014a; Harp et al., 2011). Take the Qiaojia, China $M_{\mathrm{w}} 5.1$ earthquake in 2021 as an example,

*Corresponding author: xc11111111@126.com

(c) China University of Geosciences (Wuhan) and Springer-Verlag GmbH Germany, Part of Springer Nature 2021

Manuscript received September 1, 2021.

Manuscript accepted September 13, 2021.
He et al. (2021) established an inventory map of the coseismic landslides by a moderate-sized event, including 167 slope failures, based on field investigation and visual interpretation of pre- and post-quake high-resolution images. They found that these landslides are mainly distributed in a NW-trending zone, and their density decreases with the increase of the distance from the Xiaohe-Baogunao fault, implying that this fault is the seismogenic structure of the Qiaojia event. These landslides are all located in the areas of intensity VI or higher of Ludian $M_{\text {w6.2 }}$ event, China in 2014 (Wu et al. 2020; Xu et al. 2014b). This indicates that the Ludian shock may have an impact on the landslides triggered by the Qiaojia earthquake. This study provides readers a comprehensive presentation of the landslides triggered by Qiaojia $M_{\mathrm{w}} 5.1$ earthquake, as well as an analysis for the nature of the earthquake-generating fault in terms of the distribution pattern of landslides.

The Milin earthquake in Tibet in 2017 triggered a large number of landslides, which attracted the attention of many scholars. Huang et al. (2021) established the most complete and detailed coseismic landslide map ever been recorded, containing 3130 individual ones. They analyzed the occurrence mechanism and distribution pattern of the landslides considering the correlation factors such as the elevation, slope angle, slope aspect, lithology, distance from the epicenter, and distance from the seismogenic fault. The results show that the seismogenic fault has a strong controlling effect on the landslides. This study provides a high-quality database of coseismic landslides, representing a contribution to global earthquaketriggered landslide database.

In recent years, with the development of space technology, landslide identification technology and activity analysis method based on remote sensing data have made remarkable progresses. Sensors on remote sensing satellites, unmanned aerial vehicles, ground optics and radar have been vigorously improved. The corresponding LiDAR, InSAR, optical imaging and other technologies provide strong support for landslide identification. Based on the LiDAR technology, Guo C et al. (2021) identified and classified 146 landslides within an areas of $135 \mathrm{~km}^{2}$ in Danba County, China. It provides a database for the subsequent landslide susceptibility evaluation and indicates the viability of using the LiDAR technology to create a complete and detailed landslide inventory map. Based on sentinel-1 data and InSAR technology and aided by optical image recognition and field investigations, Dai et al. (2021) identified 23 active landslides 
in the Bailong River Basin, Zhouqu County, China. It found that there is a lag effect in the influence of rainfall on landslides by analyzing the relationship between landslide movement velocity and rainfall.

Slope failures and debris flow are common geologic hazards. The slope stability analysis, susceptibility evaluation and choice of engineering control measures are of great significance for the prevention and mitigation of such geo-hazards. Taking a typical road construction on the slope in the southeast coast of China as an example, Xu et al. (2021) analyzed the stability of the cutting slope strengthened by pile anchor structure under rainfall and earthquakes by using the limit equilibrium method and pseudo static analysis. The results show that the safety factor of the slope decreases significantly with the increase of the excavation height, rainfall duration and intensity. The influence of the height on slope stability is greater than that of rainfall. The pile anchor structure reinforcement project of the slope significantly improved the stability of the slope. This study is helpful for the reasonable reinforcement of similar slopes.

Based on the dynamic centrifugal model test, Cheng et al. (2021) studied the seismic performance of a sand slope with different ground motion inputs and different slope angles. The effects of the slope angle on the slope ground acceleration, ground motion amplification coefficient and predominant period were revealed. They analyzed the permanent displacement of the slope model under different intensities and revealed the dynamic failure process of the slope, which provides a basis for the seismic design of slopes. Li et al. (2021) simulated the transformation of landslides into debris flow under different rainfall intensities by using similar material tests. Their results found that different rainfall intensities may lead to three failure modes: small instability at the front edge of the slope, local large instability and whole instability. According to the duration of rainfall and different slope failure modes, five early warning levels of landslide-debris flow were determined. This study can provide a scientific basis for the early warning of rainfall-triggered landslides and debris flows.

Seismic liquefaction is a kind of important secondary earthquake effects, which seriously threatens the safety of urban buildings. The hazard and risk assessment of urban liquefaction is of great significance for earthquake disaster prevention and reduction. Chen et al. (2021) proposed an urban regional probabilistic liquefaction hazard assessment method based on the dynamic analysis considering soil uncertainty. This new method solve the problem that the uncertainty of soil performance cannot be considered in the traditional methods. With the help of high-performance calculation, more reliable seismic liquefaction risk assessment results can be determined.

The recurrence interval of large earthquakes can be studied by dating the surface rupture zone along the active fault, which is of great significance for earthquake disaster prevention and mitigation. Wang S Y et al. (2021) investigated the Litang fault on the eastern margin of Tibetan Plateau, determined the spatial distribution of the surface ruptures caused by the 1890 earthquakes, and identified four paleoearthquakes including this event based on the dating data. This work demonstrates how to make a more objective understanding of the seismic risk in this area through the analysis of the geometric characteristics of the surface rupture distribution of the Litang fault, the temporal and spatial distribution of the large paleoearthquakes and the feature of earthquake recurrence.

Earthquake site effect is an important issue in research of earthquake hazard. Zhang et al. (2021) proposed a ground motion calculation method based on a virtual auxiliary model of equivalent input seismic loading. Different from traditional methods, the auxiliary model in this new method can solve the nonlinear mechanical problems and model the problems with arbitrary geometry. In addition, the method is applicable not only to elastic problems, but also to inelastic problems. This work provides a new method for solving the problem of three-dimensional seismic response under complex site conditions. Guo Z et al. (2021) studied the site response characteristics of double frequency microseisms on thick and loose sediments on the eastern coast of the United States through the analysis of seismic data. They found that the continental slope is a key submarine topographic feature which behaves as an obstacle causing reflections of the incoming waves and formation of standing waves resulting in the generation of double-frequency microseisms. The thick and loose sediments amplify the double-frequency microseisms increasingly with the thickening of the sediments due to the significant site effect. This work contributes a unique study on the seismic site effect evaluation of the sites with thick sediments using microseisms recordings.

The dynamic failure mechanism of faults crossing tunnels is the key problem in tunnel disaster prevention in seismically active areas. Based on the numerical simulation method, Jiao et al. (2021) studied the nonlinear response characteristics of a rock tunnel crossing a fault under the action of oblique incident seismic $\mathrm{P}$ waves. The results show that the failure mechanism of the tunnel crossing the non-seismogenic fault is the result of the joint action of ground motion and its associated local slip in the fault position. It was also found that the seismic response of the tunnel is very sensitive to the change of wave impedance ratio between the fault and surrounding rock. They further noted that the seismic response of the tunnel first increases and then decreases with the growth of the incident angle of $\mathrm{P}$ waves. This work is helpful for reliable stability calculation of tunnels crossing faults.

Understanding the rock mechanical behavior and failure mechanism in special environments is important in disaster prevention and mitigation of rock- and soil-related geologic hazards. Wang S R et al. (2021) studied the mechanical properties and mechanism of granite under the coupling action of acid corrosion and freeze-thaw cycle with granite samples and two comparative sandstone samples collected in North Tianshan near Urumqi, Xinjiang, China. The X-ray diffraction and scanning electron microscope analysis of representative granite samples confirmed the existence and composition of siliceous cement, and revealed the mechanism of the improvement of rock mechanical properties and the rock failure behavior in extreme environments.

We are glad to see the successful publication of this special issue. Here, we are particularly grateful to Shuhua Wang and Chao Shan of the Editorial Office of Journal of Earth Science for 
their strong support and help in the organization, review, modification, and verification of the manuscripts submitted to this special issue. We also thank all the authors of this issue for their contributions and all the reviewers for their valuable and constructive comments and suggestions. There are still many interesting problems about geo-disasters that deserve further studies. We hope this special issue can contribute a little to promoting the advancement of the research on geo-disasters. The final publication is available at Springer via https://doi.org/10.1007/s12583-021-1546-4.

\section{REFERENCES CITED}

Chen, J., O-tani, H., Takeyama, T., et al., 2021. A Probabilistic Liquefaction Hazard Assessment for Urban Regions Based on Dynamics Analysis Considering Soil Uncertainties. Journal of Earth Science, 32(5): 1129-1138. https://doi.org/10.1007/s12583-021-1431-1

Cheng, H. L., Zhou, J. M., Chen, Z. Y., et al., 2021. A Comparative Study of the Seismic Performances and Failure Mechanisms of Slopes Using Dynamic Centrifuge Modeling. Journal of Earth Science, 32(5): 1166-1173. https://doi.org/10.1007/s12583-021-1481-4

Dai, C., Li, W. L., Wang, D., et al., 2021. Active Landslide Detection Based on Sentinel-1 Data and InSAR Technology in Zhouqu County, Gansu Province, Northwest China. Journal of Earth Science, 32(5): 1092-1103. https://doi.org/10.1007/s12583-020-1380-0

Guo, C., Xu, Q., Dong, X., et al., 2021. Geohazard Recognition and Inventory Mapping Using Airborne Lidar Data in Complex Mountainous Areas. Journal of Earth Science, 32(5): 1079-1091. https://doi.org/10.1007/s12583-021-1467-2

Guo, Z., Huang, Y., Aydin, A., et al., 2021. Double-Frequency Microseisms on the Thick Unconsolidated Sediments in Eastern and Southeastern Coasts of United States: Sources and Applications on Seismic Site Effect Evaluation. Journal of Earth Science, 32(5): 1190-1201. https://doi.org/10.1007/s12583-021-1426-y

Harp, E. L., Keefer, D. K., Sato, H. P., et al., 2011. Landslide Inventories: The Essential Part of Seismic Landslide Hazard Analyses. Engineering Geology, 122(1/2): 9-21. https://doi.org/10.1016/j.enggeo.2010.06.013

He, X. L., Xu, C., Qi, W. W., et al., 2021. Landslides Triggered by the 2020 Qiaojia $M_{\mathrm{w}} 5.1$ Earthquake, Yunnan, China: Distribution, Influence Factors and Tectonic Significance. Journal of Earth Science, 32(5): 1056-1068. https://doi.org/10.1007/s12583-021-1492-1

Huang, Y., Cheng, H. L., 2013. The Impact of Climate Change on Coastal Geological Disasters in Southeastern China. Natural Hazards, 65(1): 377-390. https://doi.org/10.1007/s11069-012-0370-7

Huang, Y., Dai, Z. L., Zhang, W. J., 2014. SPH Models for Geo-Disasters. Geo-Disaster Modeling and Analysis: An SPH-Based Approach. Springer, Berlin, 23-49. https://doi.org/10.1007/978-3-662-44211-1_2

Huang, Y. D., Xu, C., Zhang, X. L., et al., 2021. An Updated Database and Spatial Distribution of Landslides Triggered by the Milin, Tibet $M_{\mathrm{w}} 6.4$ Earthquake of 18 November 2017. Journal of Earth Science, 32(5): 1069-1078. https://doi.org/10.1007/s12583-021-1433-Z

Jiao, H. Y., Du, X. L., Zhao, M., et al., 2021. Nonlinear Seismic Response of Rock Tunnels Crossing Inactive Fault under Obliquely Incident Seismic P Waves. Journal of Earth Science, 32(5): 1174-1189. https://doi.org/10.1007/s12583-021-1483-2

Keller, E., De Vecchio, D. E., Blodgett, R. H., 2015. Natural Hazards: Earth's
Processes as Hazards, Disasters, and Catastrophes, Pearson Higher Education AU. [2021-09-05]. https://doi.org/10.4324/9781315164298

Li, Q. Q., Huang, D., Pei, S. F., et al., 2021. Using Physical Model Experiments for Hazards Assessment of Rainfall-Induced Debris Landslides. Journal of Earth Science, 32(5): 1113-1128. https://doi.org/10.1007/s12583-020-1398-3

McGlade, J., Bankoff, G., Abrahams, J., et al., 2019. Global Assessment Report on Disaster Risk Reduction 2019, UN Office for Disaster Risk Reduction. [2021-09-05]. https://www.undrr.org/publication/global-assessment-reportdisaster-risk-reduction-2019

Ritchie, H., Roser, M., 2019. Natural Disasters. Our World in Data. [2021-09-05]. https://ourworldindata.org/natural-disasters

Vilímek, V., Wang, F., Strom, A., et al., 2020. Understanding and Reducing Landslide Disaster Risk: Volume 5 Catastrophic Landslides and Frontiers of Landslide Science. Springer Nature, Berbin

Wang, S. Y., Zhou, R. J., Liang, M. J., et al., 2021. Co-Seismic Surface Rupture and Recurrence Interval of Large Earthquakes along Damaoyaba-Litang Segment of the Litang Fault on the Eastern Margin of the Tibetan Plateau in China. Journal of Earth Science, 32(5): 1139-1151. https://doi.org/10.1007/s12583-021-1425-z

Wang, S. R., Chen, Y. L., Ni, J., et al., 2021. Mechanical Characteristics and Mechanism of Granite Subjected to Coupling Effect of Acidic Corrosion and Freeze-Thaw Cycles. Journal of Earth Science, 32(5): 1202-1211. https://doi.org/10.1007/s12583-021-1414-2

Wu, W. Y., Xu, C., Wang, X. Q., et al., 2020. Landslides Triggered by the 3 August 2014 Ludian (China) $M_{\mathrm{w}} 6.2$ Earthquake: An Updated Inventory and Analysis of Their Spatial Distribution. Journal of Earth Science, 31(4): 853-866. https://doi.org/10.1007/s12583-020-1297-7

Xiong, M., Huang, Y., 2019. Novel Perspective of Seismic Performance-Based Evaluation and Design for Resilient and Sustainable Slope Engineering. Engineering Geology, 262: 105356. https://doi.org/10.1016/j.enggeo.2019.105356

$\mathrm{Xu}$, C., 2015. Preparation of Earthquake-Triggered Landslide Inventory Maps Using Remote Sensing and GIS Technologies: Principles and Case Studies. Geoscience Frontiers, 6(6): 825-836. https://doi.org/10.1016/j.gsf.2014.03.004

Xu, X. W., Xu, C., 2021. Natural Hazards Research: An Eternal Subject of Human Survival and Development. Natural Hazards Research, 1(1): 1-3. https://doi.org/10.1016/j.nhres.2020.12.003

Xu, C., Xu, X. W., Yao, X., et al., 2014a. Three (Nearly) Complete Inventories of Landslides Triggered by the May 12, 2008 Wenchuan $M_{\mathrm{w}} 7.9$ Earthquake of China and Their Spatial Distribution Statistical Analysis. Landslides, 11(3): 441-461. https://doi.org/10.1007/s10346-013-0404-6

$\mathrm{Xu}, \mathrm{C} ., \mathrm{Xu}, \mathrm{X}$. W., Shen, L. L., et al., 2014b. Inventory of Landslides Triggered by the $2014 M_{\mathrm{s}} 6.5$ Ludian Earthquake and Its Implications on Several Earthquake Parameters. Seismology and Geology, 36(4): 1186-1203 (in Chinese with English Abstract)

Xu, X., Han, Z., Yang, X., et al., 2016. Seismotectonic Map in China and Adjacent Regions. Seismogical Press, Beijing

Xu, X., Xing, Y. C., Guo, Z., et al., 2021. Stability Analysis of RainfallTriggered Toe-Cut Slopes and Effectiveness Evaluation of Pile-Anchor Structures. Journal of Earth Science, 32(5): 1104-1112. https://doi.org/10.1007/s12583-021-1474-3

Zhang, X. L., Peng, X. B., Li, X. J., et al., 2021. Three-Dimensional Seismic Response in Complex Site Conditions: A New Approach Based on an Auxiliary-Model Method. Journal of Earth Science, 32(5): 1152-1165. https://doi.org/10.1007/s12583-021-1471-6 